\title{
$\mathbb{A}$ Economics Bulletin
}

Volume 35, Issue 3

\section{Completed fertility effects of family policy measures: evidence from a life- cycle model}

\author{
Holger Stichnoth \\ ZEW Mannheim
}

\author{
Raphael Abiry \\ ZEW Mannheim and Goethe University Frankfurt
}

\author{
Karsten Reuss \\ ZEW Mannheim and VDI Technologiezentrum Düsseldorf
}

\begin{abstract}
We estimate a structural life-cycle model of fertility and female labour supply and use it to evaluate the effects of a number of key family policy measures based on data for Germany. Parental leave benefits, child benefits and subsidized childcare are found to have substantial fertility effects. Without these measures, completed fertility is estimated to be lower by $6 \%, 7 \%$, and $10 \%$, respectively. Income tax splitting, which is fiscally expensive, reduces female labour supply but has a negligible effect on fertility.
\end{abstract}

Work on this paper began as part of a project financed by the German Federal Ministry of Finance (BMF) and the Federal Ministry of Family Affairs, Senior Citizens, Women and Youth (BMFSFJ). The views expressed in the paper are those of the authors and not necessarily those of the two ministries. Holger Bonin (ZEW Mannheim), Christina Boll, Nora Reich, Christina B. Wilke (all at HWWI Hamburg), Marc-André Nehrkorn-Ludwig, Reinhold Schnabel (both at the University of Duisburg-Essen), Irene Gerlach, Inga Laß (both at FFP Münster) and Karsten Hank (University of Cologne) participated in the overall project and provided valuable input into the development of the present model. The manuscript benefitted from comments by Bertrand Koebel, François Laisney and Alexander Ludwig and from discussions with seminar participants at ZEW Mannheim, NIW Hannover, the Institute for Fiscal Studies (London) and ISER/University of Essex, workshop participants at the ZEW Workshop on Family Economics (November 2013), the ZEW Workshop on Family Policy in Germany (February 2014) and the 4th Workshop "Arbeitsmarkt und Sozialpolitik" at ifo Dresden as well as conference participants at the meetings of the SMYE (Vienna), the IIPF (Lugano) and the EALE (Ljubljana). Financial support through the SEEK programme of the State of Baden-Württemberg is gratefully acknowledged.

Citation: Holger Stichnoth and Raphael Abiry and Karsten Reuss, (2015) "Completed fertility effects of family policy measures: evidence from a life-cycle model", Economics Bulletin, Volume 35, Issue 3, pages 1726-1733

Contact: Holger Stichnoth - stichnoth@zew.de, Raphael Abiry - abiry@zew.de, Karsten Reuss - kreuss@arcor.de.

Submitted: February 19, 2015. Published: August 12, 2015. 


\section{Introduction}

Although spending on family policy measures is quite considerable in many countries, relatively little is known about the effects of these measures, in particular with respect to long-run fertility outcomes. ${ }^{1}$ Quasi-experimental studies on the effects of family policies on fertility focus on the short-run effects (e.g. Cygan-Rehm, 2014; Raute, 2014). Likewise, the structural models of Haan and Wrohlich (2011) and Stichnoth (2014) assume a oneyear decision horizon and therefore cannot analyze the effects on completed fertility.

In this paper, we develop a structural life-cycle model that allows us to quantify the effects of parental leave benefits and three other key family policy measures (subsidized childcare, child benefits, income tax splitting) on completed fertility. The model is estimated using data from the German Socio-Economic Panel (SOEP); the simulation of disposable incomes is based on a detailed representation of the tax-transfer system and models the cost and availability of childcare based on new data from the SOEP extension FiD ("Familien in Deutschland").

Francesconi (2002) develops a dynamic model with endogenous fertility for the US. While he focuses on women who are always married, we include all women and model marriage as an exogenous stochastic process. Moreover, we consider not only the number, but also the age of children, allow for stochastic fertility, model disposable income as opposed to gross earnings and incorporate demand restrictions on the labour market by allowing for (exogenous) job offer and break-up rates. Adda et al. (2011) allow for occupation-specific wage-experience profiles and endogenize the initial occupation decision. However, they study women who go through the German system of apprenticeship training, while we also include women with tertiary education, a group that is important in the discussion about (low) fertility. Importantly, Adda et al. focus on the decomposition of the career costs of children and less on the evaluation of specific policies. The model by Slonimczyk

\footnotetext{
${ }^{1}$ In Germany, the country on which we focus here, spending on four key measures (parental leave benefits, subsidized childcare, child benefits, income tax splitting) alone totals around 70 billion euros per year (BMFSFJ, 2008).
} 
and Yurko (2014) is also closely related to ours; they study the effects of the maternity capital policy in Russia.

\section{The Model}

We develop a dynamic discrete choice model of women's fertility and employment choices from their mid-20s (when education is typically completed) until the end of the fertile phase. We assume a finite horizon of $T=20$ discrete periods, each of which corresponds to one year.

Women decide optimally in each period given their expectations about all future periods. Fertility is stochastic in the model: the probability of becoming pregnant within one year when trying to conceive depends on age. In addition, we allow for permanent infertility as an absorbing state. Finally, we make fertility dependent on marital status by assuming that women can only have children if they live with a partner. ${ }^{2}$ Marriage and divorce are modelled as exogenous stochastic processes; for simplicity, all husbands are assumed to work full-time and to earn the same income (see the Online Appendix for details). ${ }^{3}$ We take into account that women cannot always transit between the employment states (not employed, part-time, full-time): whether a transition is possible depends on state-specific job offer rates. Moreover, a woman may lose her current job, with exogenous break-up rate.

Women anticipate that a reduction in their labour supply leads to a loss of work experience and hence of future earnings opportunities. This drives the dynamics of the model and the interaction between fertility and employment choices. In addition, fertility has an

\footnotetext{
${ }^{2}$ For Germany and the age groups considered here, this approximates actual birth patterns very closely. See the discussion paper version of this article for an alternative specification in which we relax the assumption.

${ }^{3}$ Making the match dependent on the woman's income would add additional realism and would introduce additional dynamics into the model. Other things equal, it would reinforce women's incentive to increase their earnings when single. During marriage, the effect will depend on whether the income of the husband is higher or lower than in the present formulation of the model. Finally, one could think about making divorce probabilities dependent on women's earnings, or perhaps on relative earnings, as suggested by the economics of the family. We leave this for future work.
} 
impact on the formation and dissolution of couples, as the exogenous stochastic (Markov) processes through which these are modelled depend (among other things) on the number of children.

Let $\boldsymbol{x}_{i t}$ denote the vector of (discretized) state variables for woman $i$ in period $t$. The elements of the vector are the female employment status, the years of work experience $(0,1,4,12)$, the number of children $(0,1,2,3)$ and the age of the youngest child $(0,1,3,10)$, as well as indicators for permanent infertility and for the presence of a partner.

Given the state variables and her expectations about future periods, the woman chooses a vector of actions $\boldsymbol{a}_{i t}$ : her desired employment state and whether she tries to conceive; there are thus six possible choices.

She solves the dynamic programming problem given by

$$
V_{i t}\left(\boldsymbol{x}_{i t}, \boldsymbol{\theta}\right)=\max _{\left\{a_{i s}\right\}_{t}^{T}}\left\{\sum_{s=t}^{T} \beta^{s-t} \mathbb{E}_{t}\left[u\left(\boldsymbol{x}_{i s}, \boldsymbol{\theta}\right) \mid \boldsymbol{a}_{i t}\right]\right\}
$$

Consumption equals disposable income in each period; the latter is simulated using a fairly detailed representation of the German tax-transfer system (see the Online Appendix for details).

The instantaneous utility function is assumed to be linear in its parameters $\boldsymbol{\theta}$. $\beta$ is the one-period discount factor. The expectation is with respect to the state transition probabilities $\operatorname{Pr}_{t}\left(\boldsymbol{x}_{i, t+s} \mid \boldsymbol{x}_{i t}, \boldsymbol{a}_{i t}\right)$, which depend on the current state $\boldsymbol{x}_{i t}$ and on the action $\boldsymbol{a}_{i t}$ and act as a constraint on the maximization problem.

A key component of the model is the accumulation of work experience. Each additional year of full-time work is assumed to increase experience by one unit, while each year of part-time work leads to an increase of 0.1 units. ${ }^{4}$ If a woman does not work, her work experience remains constant. Wages increase with accumulated experience. As a result,

\footnotetext{
${ }^{4}$ Recent studies have suggested that returns to part-time experience are much lower than returns to full-time work. The value of 0.1 is inspired by the findings of Blundell et al. (2013). Results for an alternative specification (with a value of 0.5 ) are available in the discussion paper version of the article.
} 
a career break after child birth is not only costly in terms of foregone current earnings, but also affects future wage offers negatively. We assume that the logarithm of hourly wages is a deterministic function of experience and experience squared.

For every parametrization $\boldsymbol{\theta}$, the dynamic programming problem is solved by backwards induction. We take into account that there are utility components of each option that are observed by the woman, but not by the econometrician. We assume these to be iid extreme value. With this assumption, the policy function in our model is a vector of six logistic choice probabilities.

\section{Data and Estimation}

We use the 1995-2010 waves of the German Socio-Economic Panel (SOEP) ${ }^{5}$ to estimate the parameters of the exogenous stochastic processes (household formation and separation, wage-experience profile). ${ }^{6}$ The age-specific fecundity rates (i.e., the probability of giving birth within one year of unprotected sexual intercourse) and the probability of being permanently infertile are calibrated based on data from the Fertility Sourcebook (Khatamee and Rosenthal, 2002). We set the discount factor $\beta$ to 0.98, a typical value in the literature (e.g. Attanasio et al., 2008; Blundell et al., 2013). The annual job break-up rate is set to 0.1. Concerning the transitions between employment states, we assume that a woman who worked full-time in the previous period can keep her full-time job if she wants to, unless she becomes involuntarily unemployed. By contrast, a woman who worked part-time and decides to move to a full-time job will only be successful with a probability of $70 \%$.

The 18 parameters of the utility function are estimated based on 44 cross-sectional moments from the SOEP wave of 2010. The moments are based on the joint distribution of the employment state and the number of children at four different ages $(26,32,39,45)$.

\footnotetext{
${ }^{5}$ The SOEP, which started in 1984, is a longitudinal survey of private households, with a rich set of information on personal and household characteristics. See Wagner et al. (2007) for a detailed description.

${ }^{6}$ Results available from the authors upon request.
} 
We consider women aged 25 to 29 and use the dynamic model to simulate trajectories over 21 periods (including the initial period), i.e. until the end of their fertile years at ages 45 to $49 .{ }^{7}$ The stochastic elements are introduced by drawing from the distributions for the exogenous stochastic processes and from the vector of choice probabilities.

The objective function is the sum of squared differences between the sample moments and the moments generated by the model. As we have closed-form expressions for the choice probabilities, we can derive exact expressions for the model moments.

The estimated utility parameters are shown in Table 1, while the deviations between observed and simulated moments are documented in the Online Appendix. Overall, the model fits the sample moments well, although we found the intensive margin (part-time vs. full-time) more difficult to reproduce than the employment decision.

Our baseline simulation predicts that women aged 25 to 29 will have on average 1.52 children at the end of their fertile phase. $25 \%$ of women will remain childless, and $15 \%$, $42 \%$ and $18 \%$ of women will give birth to one, two, and more than two children, respectively. As shown in the Online Appendix, the simulation predicts a strongly negative relationship between the number of children and the number of years spent in full-time work.

\section{Policy Experiments}

Table 2 shows the results for our counterfactual policy experiments. Each row of the table is from a separate experiment in which we switch off the corresponding measure and keep the remaining rules of the 2012 tax-transfer-system in place. The interactions within the system are taken into account. For instance, abolishing child benefits does not

\footnotetext{
${ }^{7}$ We group several birth cohorts to increase the sample size. As expected given their young age (mean: 27 , std.dev.: 1.4), relatively few of the 392 women $(33 \%)$ are married in the initial period, and $60 \%$ do not have children ( $22 \%$ have one child, $14 \%$ have two children, and $5 \%$ have more than two children). $45 \%$ of the children are below the age of three, $44 \%$ are between three and six, and $11 \%$ are older than six. $30 \%$ of the women are not employed when we initially observe them, $24 \%$ work part-time and $46 \%$ work full-time. They have on average 3.1 years of work experience; the mean wage offer is 11.5 euros per hour.
} 
Coefficient (Std.err.)

Disposable income

One child

$-439.5(80.2)$

Two children

$-1076.7(79.3)$

More than two children

$-4261.8(107.1)$

Partner ${ }^{*}$ children $>0$

$4994.9(0.3)$

Part-time

$-38.8(16.8)$

Not employed

$-686.0(81.3)$

Part-time ${ }^{*}$ one child

$-2098.5(99.8)$

Part-time ${ }^{*}$ two children

$804.7(61.2)$

Part-time ${ }^{*}$ more than two children

$1656.1(63.8)$

Part-time ${ }^{*}$ age youngest child $<3$

$-886.0(92.9)$

Part-time ${ }^{*}$ age youngest child $\in[3,10)$

$3204.5(89.7)$

Part-time $*$ age youngest child $\geq 10$

$-719.0(65.6)$

Not employed * one child

$-1027.5(110.2)$

$528.2(91.2)$

Not employed $*$ two children

3403.1 (63.5)

Not employed $*$ age youngest child $<3$

$974.0(83.3)$

Not employed * age youngest child $\in[3,10)$

$3588.4(88.6)$

Not employed $*$ age youngest child $\geq 10$

$-10333.8(29.1)$

Source: SOEP 2010. N=392. Standard deviations from 250 bootstrap runs shown in parentheses, using the point estimates for the original sample as the starting value in each case. Disposable income is divided by the number of adults in the households. The coefficient on disposable income is normalized to 1 .

lead to a one-to-one income reduction as some households may become eligible for social assistance.

The model predicts that abolishing child benefits, parental leave benefits, or subsidized childcare would reduce completed fertility by $0.5 \%, 1.4 \%$, and $2.2 \%$, respectively, compared with the baseline simulation. Income tax splitting, which is fiscally expensive, reduces female labour supply but has a negligible and statistically insignificant effect on fertility.

\section{Conclusion}

Based on a structural life-cycle model of fertility and female labour supply, this paper has estimated the effects of key family policy measures on completed fertility in Germany. 
Table 2: Main results

\begin{tabular}{lcccc}
\hline & & \multicolumn{2}{c}{ Employment (years) } \\
\cline { 3 - 4 } & $\begin{array}{c}\text { Completed } \\
\text { fertility }\end{array}$ & $\begin{array}{c}\text { Not } \\
\text { employed }\end{array}$ & $\begin{array}{c}\text { Part- } \\
\text { time }\end{array}$ & $\begin{array}{c}\text { Full- } \\
\text { time }\end{array}$ \\
\hline Child benefits & -0.007 & -0.005 & 0.107 & -0.102 \\
Income tax splitting & $(0.004)$ & $(0.011)$ & $(0.015)$ & $(0.017)$ \\
Parental leave benefits & -0.002 & -0.053 & 0.011 & 0.041 \\
& $(0.004)$ & $(0.014)$ & $(0.017)$ & $0.015)$ \\
Subsidized childcare & -0.021 & -0.049 & -0.024 & $(0.025)$ \\
& $(0.007)$ & $(0.020)$ & -0.109 & -0.159 \\
& -0.034 & 0.268 & $(0.051)$ & $(0.033)$ \\
\hline
\end{tabular}

Source: Own simulations based on SOEP 2010 and the tax-transfer system of 2012. T=21 periods, each corresponding to one year. The simulation sample consists of 50 clones of each of the 392 women in the original sample. The table shows absolute changes with respect to the baseline scenario. Each line corresponds to a different scenario. Standard errors in parentheses based on 250 bootstrap runs.

For some of the measures, such as parental leave benefits, these are the first estimates of a long-run nature, as existing quasi-experimental studies focus on the short run and cannot distinguish between timing effects and effects on completed fertility.

Future research should refine the estimates by using (administrative) data on complete employment biographies, and by allowing for unobserved heterogeneity in preferences and ability as well as for a more complex relationship between work experience and wages.

\section{References}

Adda, J., C. Dustmann, and K. Stevens (2011). The career costs of children. IZA Discussion Paper 6201, Bonn.

Attanasio, O., H. Low, and V. Sanchez-Marcos (2008). Explaining changes in female labor supply in a life-cycle model. American Economic Review 98(4), 1517-1552.

Blundell, R., M. Costas Dias, C. Meghir, and J. Shaw (2013). Female labour supply, human capital and welfare reform. Working Paper W13/10, IFS, London. 
BMFSFJ (2008). Familienbezogene Leistungen und Massnahmen des Staates im Jahr 2008. Berlin.

Cygan-Rehm, K. (2014). Wirkungen des Elterngeldes auf die Fertilität - zum Stand der Kenntnis. Vierteljahrshefte zur Wirtschaftsforschung 83(1), 145-162.

Francesconi, M. (2002). A joint dynamic model of fertility and work of married women. Journal of Labor Economics 20(2), 336-380.

Haan, P. and K. Wrohlich (2011). Can child care policy encourage employment and fertility? Evidence from a structural model. Labour Economics 18(4), 498-512.

Khatamee, M. and M. Rosenthal (2002). The Fertility Sourcebook. New York: McGrawHill Contemporary.

Raute, A. (2014). Do financial incentives affect fertility? Evidence from a reform in maternity leave benefits. University College London.

Slonimczyk, F. and A. Yurko (2014). Assessing the impact of the maternity capital policy in Russia. Labour Economics 30, 265-281.

Stichnoth, H. (2014). Short-run fertility effects of family policy measures: Evidence from a structural model. Discussion Paper 14-069, ZEW, Mannheim.

Wagner, G. G., J. R. Frick, and J. Schupp (2007). The German Socio-Economic Panel Study (SOEP): Scope, evolution and enhancements. Schmollers Jahrbuch - Journal of Applied Social Sciences Studies 127(1), 139-169. 